\title{
The EEG in Huntington's chorea: a clinical and neuropathological study
}

\author{
D. F. SCOTT, K. W. G. HEATHFIELD, B. TOONE ${ }^{1}$, \\ AND J. H. MARGERISON ${ }^{2}$ \\ From the EEG Department, the London Hospital, London, the Neurological Department, \\ Whipps Cross Hospital, London, and the Department of Clinical Neurophysiology, \\ St. Bartholomew's Hospital, London
}

SUMMARY The EEGs are reported on a group of 95 patients with Huntington's chorea. Thirty one showed little activity of any kind, and in particular no alpha rhythm above $10 \mu \mathrm{V}$ in amplitude was seen. Only those records which still met these criteria when re-examined were included in the 'low voltage' category. EEGs in this category occurred significantly more frequently in institutionalized patients and in those with a positive family history of Huntington's chorea, dementia, and choreiform movements together. Computer averaged responses to light and sound were found in the three patients examined, though their routine EEGs were low voltage. Neuropathological examination confirmed a clinical diagnosis of Huntington's chorea in 14 patients investigated. There was a statistically significant association between cortical atrophy, including the frontal lobe, and a 'low voltage' EEG. It was concluded that the low voltage record, though not specific for Huntington's chorea, was rare in other neurological disorders. The EEG is therefore of value in patients suspected of having Huntington's chorea as well as in various presenile dementias.

There have been several accounts of the electroencephalographic (EEG) findings in Huntington's chorea (Gibbs and Gibbs, 1941; Hill, 1948; Leese, Pond, and Shields, 1952). However, the numbers in these studies were small and, though clinical details were given, none included neuropathological information. The largest series (Hill, 1948) consisted of only six patients, five of whom showed 'absence of rhythmical activity ... a at rest, on eye closure, and during overbreathing'. In particular, the alpha activity was small in amount and of low amplitude.

More recently, two of the present authors, Margerison and Scott (1965), studied a larger series of 25 patients, confirming the earlier observations of Hill (1948). Since that report, repeat EEGs have been carried out on some of those patients as well as enlarging the total number of patients examined.

The present study is of 95 patients and investigates possible relationships of the low amplitude EEG with clinical features including dementia, duration of illness, and family history. As well

\footnotetext{
1 Present address: Maudsley Hospital, Denmark Hill, London S.E.5. 2 Died 4 August 1970 while this work was in progress.
}

as conventional EEGs, computer averaged evoked potentials were examined in three patients and serial recordings in 12 patients. There was also neuropathological information on 14 patients. Using this, an attempt was made to test the hypothesis of Hill (1948) that 'the association of an atrophic process in the frontal cortex and in the basal ganglia is the significant factor (in producing the low voltage EEG) since neither alone produces either persistent depression or facilitation of cortical rhythm'.

\section{METHOD}

Ninety-five patients with Huntington's chorea were studied. They came from the North East Metropolitan Regional Hospital Board area (Heathfield, 1967) and the county of Bedfordshire (Heathfield and Mackenzie, 1971). As a result, many of the patients in the series were examined personally (K.W.G.H.). The rest were studied at The Bethlem and Maudsley Hospitals and other parts of South East England. Most of the EEGs were carried out at the clinical neurophysiology departments of Goodmayes, The London, Oldchurch, St. Bartholomew's, and Severalls Hospitals during the period 1950 to 1970 . There 


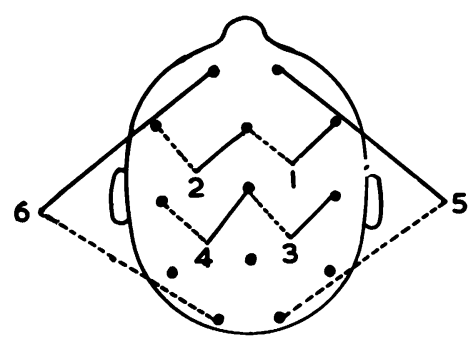

HF 25 CPS

TC 0.3 SEC

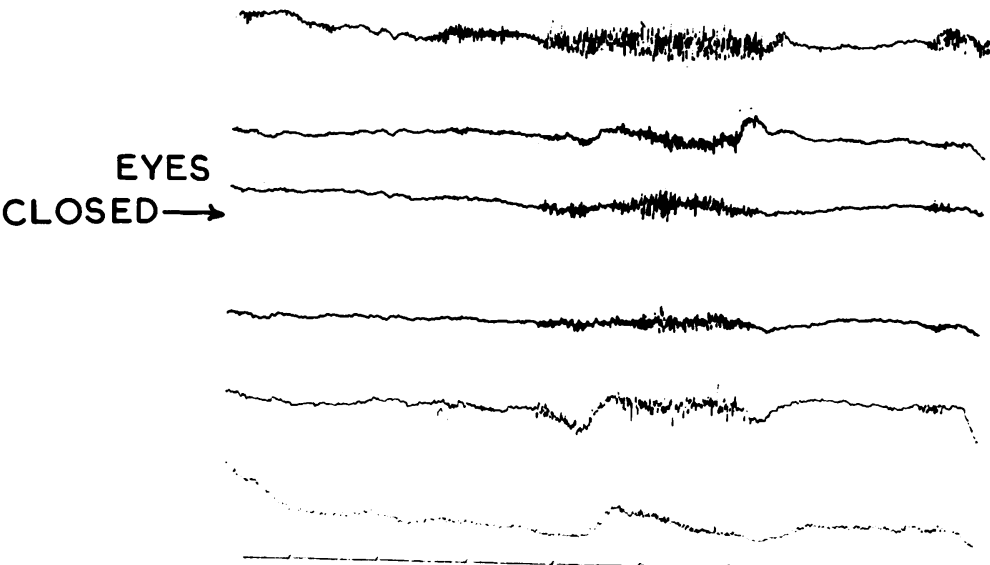

I $50 \mu \mathrm{v}$

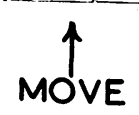

FIG. 1. EEG shows little rhythmic activity with the eyes closed. The man, aged 44, had marked choreiform movements with dementia and had been ill for six years. His family history was doubtful. He died four years later of myocardial degeneration. The brain showed severe dilatation of the anterior horns with marked shrinkage of the striatum. The caudate nucleus was only 2 to $3 \mathrm{~mm}$ thick at the level of the interventricular foramen and the lentiform nucleus was also small.
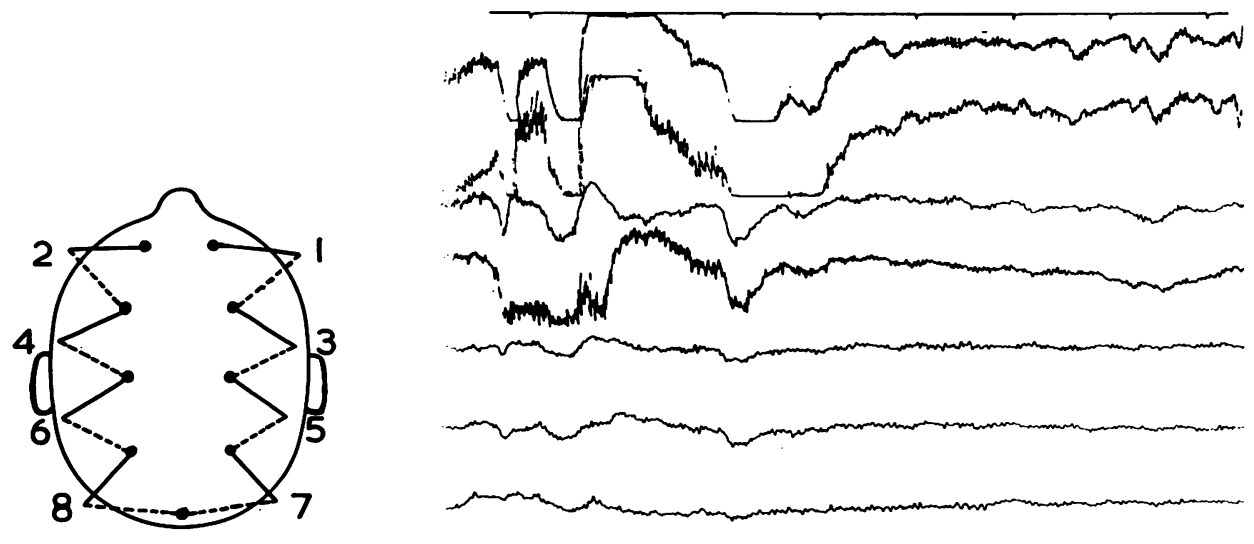

FIG. 2. EEG shows very low voltage fast activity on eye closure. A few alpha elements can be seen but they are less than $10 \mu \mathrm{V}$ in amplitude. This man, with a positive family history of mental illness but not of Huntington's chorea, had been ill for approximately four years. He had an abnormal gait and choreiform movements. He later became demented with marked chorea. At necropsy, some 11 years later, the brain showed the classical features of Huntington's chorea, the anterior horns were greatly enlarged and the head of the caudate nucleus reduced to a narrow ribbon 3 to $4 \mathrm{~mm}$ wide. The putamen was also small on both sides, the pallidum less so. The cortical ribbon appeared slightly narrow. 
Hospital, Minnesota, U.S.A., on whom evoked potential studies were performed.

The description of Hill (1948) was used and qualified so that the 'positive' category of EEGs consisted of those records which did not show any sort of activity, including alpha, of amplitude greater than $10 \mu \mathrm{V}$. Examples of this category of EEG are shown in Figs 1 and 2. The term 'flat' which had sometimes been employed for this kind of low voltage record was avoided, as it could be confused with the other definitions of flat (Adams, 1959). All records placed in the positive category had been examined by at least one of the authors. Of the total of 95 EEGs, 14 were not available for re-examination, often because they had been destroyed, and for these it was necessary to rely on the original reports. In order to maintain stringent criteria for the positive category none of the 'unseen' records was included in that particular group.

Three patients had evoked potential studies carried out in addition to routine EEG recording. A computer of average transients was employed in an attempt to obtain responses to light, sound, and somatosensory stimulation (Bickford, Jacobson, and Cody, 1964). For the photic stimulation runs of 100 flashes at 2 flashes/sec were used with bipolar parieto-occipital electrodes. Auditory stimulation was carried out using 'clicks' at $1 / \mathrm{sec}$ delivered through earphones with vertex and posterior auricular electrodes referred to the nose. In two of the three patients median nerve stimulation was performed with electrodes placed approximately over the contralateral somatosensory area and referred either to the nose or the 7th cervical vertebra.

Detailed neuropathological investigations were carried out by Dr. J. A. N. Corsellis in 12 of our 14 patients and by Professor Henry Urich in two. They furnished reports without prior knowledge of the EEG findings.

\section{RESULTS}

Ninety-five EEGs were used in this part of the study, one per patient. Where there were serial records (see below) the latest one was assessed and included in this particular part of the study. There were 31 positive and 64 negative EEGs. In the former group 14 were from males and 17 from females. In the latter there were 27 from males and 37 from females. The average age at the time when the EEG was taken was similar in the two categories, 46.7 years in the positive and 48.6 years in the negative. The duration of illness of the two categories was 7.7 and 6.0 years respectively.

The negative records were sometimes normal or showed some non-specific abnormality such as a mild excess of theta activity. Localized changes were uncommon, but one patient, for example, did show delta foci and at post mortem examination had metastatic deposits from a bronchial carcinoma. In 21 there was, however, plentiful alpha activity in excess of $10 \mu \mathrm{V}$, though it never exceeded $25 \mu \mathrm{V}$.

The incidence of dementia, including its severity, in the two groups at the time of the EEG recording is shown in Table 1 , and the occurrence of a positive family history in Table 2 .

TABLE 1

SEVERITY OF DEMENTIA AT TIME OF EEG (95 PATIENTS)

\begin{tabular}{cccc}
\hline & $\begin{array}{c}\text { No } \\
\text { dementia }\end{array}$ & $\begin{array}{c}\text { Moderate } \\
\text { dementia }\end{array}$ & $\begin{array}{c}\text { Serere } \\
\text { dementia }\end{array}$ \\
\hline $\begin{array}{c}\text { (31 patients) } \\
\text { 'Positive' EEG }\end{array}$ & 7 & 21 & 3 \\
(64 patients) & 23 & 36 & 5 \\
\hline
\end{tabular}

$(0 \cdot 3<\mathrm{P}>0 \cdot 2)$

TABLE 2

INCIDENCE OF POSITIVE FAMILY HISTORY (95 PATIENTS)

\begin{tabular}{ccc}
\hline & Absent or doubtful & Present \\
\hline $\begin{array}{c}\text { (31 patients) } \\
\text { ' } \begin{array}{c}\text { Negative' EEG } \\
\text { (64 patients) }\end{array}\end{array}$ & 9 & 22 \\
\hline
\end{tabular}

$(0 \cdot 2<\mathrm{P}>0 \cdot 1)$

There is a tendency for an association between both of these separately and a positive EEG, although in neither case did it reach statistical significance. The association of dementia, chorea, and positive family history together was examined in 95 patients. Eighteen of the 31 who had this cluster of features had a positive EEG, while only 15 of the 64 who had a negative EEG showed this cluster despite the fact that the average duration of illness was similar in the two EEG categories ( 7.5 years and 6.6 years respectively). These differences reached statistical significance $(0.01<P>0.001)$. In six patients of the whole series the EEG was positive within three years of the beginning of the condition.

As some of the patients were in mental hospitals while others were at home when first seen, the occurrence of positive and negative EEG features in relation to whether or not the patient was institutionalized was examined (see Table 3). Of the 65 in hospital 25 had a positive 
TABLE 3

RELATIONSHIP BETWEEN WHERE PATIENT WAS FIRST EXAMINED AND EEG FINDINGS

\begin{tabular}{lcc}
\hline & $\begin{array}{c}\text { 'Positive' } \\
\text { EEG }\end{array}$ & $\begin{array}{c}\text { 'Negative' } \\
\text { EEG }\end{array}$ \\
\hline $\begin{array}{c}\text { Seen when patient in mental } \\
\text { hospital (65 patients) }\end{array}$ & 25 & 40 \\
$\begin{array}{c}\text { Seen at home or in outpatient } \\
\text { department (30 patients) }\end{array}$ & 6 & 24 \\
\hline Total & 31 & 64 \\
\hline
\end{tabular}

$(0 \cdot 1<\mathbf{P}>0.05)$

and 40 a negative EEG. In contrast, six out of the 30 seen at home or in outpatients had a positive and 24 had a negative EEG. These results reached statistical significance.

SERIAL EEG FINDINGS Much of the information in this study was based on a single EEG carried out as part of the diagnostic procedure early in the illness. There was however information on serial EEGs in 12 patients (although only one from each was included in the overall total of 95). The serial records were performed in many instances at six monthly or yearly intervals and the number of recordings varied from three to seven. In eight the follow-up period was three years or less, although in four patients it was four, six, seven, and 10 years respectively. When the follow-up period was brief no significant change was noted. In the four patients with longer periods, three had positive EEGs throughout the whole time, the other showed some low voltage alpha activity at about $20 \mu \mathrm{V}$ in the initial recording but this had disappeared 10 years later.
One other patient, aged 9 years when first examined, was followed for three years. He was the youngest in the study and had a family history of Huntington's chorea but showed no chorea and, though not actually demented, he was aggressive and psychotic. His EEGs were examined by three independent observers including two of the authors. They came to the same conclusion that background rhythms were abnormally fragmented, particularly the alpha, and this was scanty and of lower amplitude than would be expected for a normal person of this age, although it could reach 30 to $50 \mu \mathrm{V}$ at times. Three of the patients had had epileptic attacks; in two they were of grand mal type. In these two, although the EEG record showed an excess of theta activity, there were no specifically epileptic features. The other patient who had temporal lobe attacks showed a discharging focus in the left temporal region. In all three, alpha activity was observed clearly and well above $10 \mu \mathrm{V}$ in amplitude.

EVOKED POTENTIAL STUDIES Three patients, one male and two females, had their averaged evoked responses investigated using a computer of average transients. All had been institutionalized for many years. They had EEGs in the positive category and no evoked responses were visible to visual inspection of the 'raw' trace. Their average age was 47 years and the duration of the illness ranged from seven to 27 years with an average of $16 \cdot 3$ years. All three were demented and showed marked choreiform movements. Two had a family history of this disorder. Welldefined responses to photic stimulation as well

TABLE 4

NEUROPATHOLOGICAL INFORMATION IN 14 PATIENTS

\begin{tabular}{|c|c|c|c|c|c|c|c|c|}
\hline \multirow[t]{2}{*}{ Patient } & \multirow[t]{2}{*}{ Sex } & \multirow{2}{*}{$\begin{array}{c}E E G \\
\text { findings }\end{array}$} & \multirow{2}{*}{$\begin{array}{c}\text { Time } \\
\text { between } \\
\text { EEG and } \\
\text { death }(y r)\end{array}$} & \multirow{2}{*}{$\begin{array}{c}\text { Age at } \\
\text { death } \\
(y r)\end{array}$} & \multirow{2}{*}{$\begin{array}{l}\text { Brain } \\
\text { weight } \\
(g)\end{array}$} & \multicolumn{3}{|c|}{ Atrophy in } \\
\hline & & & & & & Caudate & Striatum & $\begin{array}{c}\text { All cortical } \\
\text { areas }\end{array}$ \\
\hline 1 & $\mathrm{~F}$ & + & 6 & 61 & 985 & + & + & ++ \\
\hline 2 & $F$ & + & 11 & 67 & 1,330 & ++ & + & ++ \\
\hline 3 & M & + & 2 & 43 & 1,550 & + & + & ++ \\
\hline 4 & $\mathbf{M}$ & + & 3 & 73 & 1,035 & ++ & + & +++ \\
\hline 6 & $\mathrm{~F}$ & - & 10 & 48 & 1,065 & + & ++ & ++ \\
\hline 7 & $\mathbf{M}$ & - & 3 & 43 & 1,340 & + & + & + \\
\hline 8 & $\mathbf{M}$ & + & 12 & 48 & 1,295 & ++ & ++ & ++ \\
\hline 9 & M & + & 12 & 56 & 1,230 & ++ & ++ & ++ \\
\hline 10 & $\mathbf{M}$ & + & 4 & 59 & 1,030 & ++ & ++ & ++ \\
\hline 11 & $\mathrm{~F}$ & - & 2 & 70 & 1,280 & ++ & ++ & ++ \\
\hline 12 & $\mathbf{F}$ & - & 13 & 69 & 1,195 & ++ & + & ++ \\
\hline 13 & $\mathrm{~F}$ & - & 6 & 74 & n.k & + & + & - \\
\hline 14 & $\mathbf{M}$ & - & 11 & 56 & $\mathrm{n} . \mathrm{k}$ & + & + & - \\
\hline
\end{tabular}

$+=$ positive $;-=$ negative . 
as vertex responses to auditory stimulation were obtained in all three. In two of the three, somatosensory responses were found, and the other patient was uncooperative.

NEUROPATHOLOGICAL DATA The detailed neuropathological examination in 14 patients confirmed the clinical diagnosis of Huntington's chorea (Table 4). The salient features found were atrophy of the caudate nucleus and other striatal structures. Eleven brains showed widespread cortical atrophy including changes in the frontal lobes, and an attempt was made to relate these features to the EEG (Table 5). In spite of

TABLE 5

RELATIONSHIP BETWEEN GENERALIZED CORTICAL ATROPHY INCLUDING FRONTAL INVOLVEMENT (DETERMINED NEUROPATHOLOGICALLY) AND EEG FINDINGS

\begin{tabular}{lcc}
\hline Cortical atrophy & EEG positive & EEG negative \\
\hline Present & 7 & 4 \\
Absent & 0 & 3 \\
\hline
\end{tabular}

$(0.05<\mathrm{P}>0.02)$

the fact that the length of time between the EEG and a neuropathological examination exceeded 10 years in six patients, there was a statistically significant association between generalized cortical atrophy, including frontal lobe changes, and a positive EEG. There appeared to be no relationship between parieto-occipital atrophy and the EEG findings.

\section{DISCUSSION}

Hill (1948) observed that the EEG in organic brain disease tended 'to be more abnormal in the inflammatory than in the degenerative cases'. He also recognized for the first time that the absence of rhythmical activity was characteristic of Huntington's chorea, noting it in five of six patients investigated. His findings were supported by Margerison and Scott (1965) who reported low voltage records in 15 out of 25 patients. When atypical cases were eliminated, they found that the positive EEG occurred in 13 out of 17 patients. Other authors, notably Adams (1959), commented on the occurrence of so-called 'flat' EEG, a term avoided here because of confusion with the isoelectric EEG after cerebral catastrophes. He found it in $10 \%$ of adults without neurological and psychiatric disorder and in $13 \%$ of a variety of neurological and psychiatric conditions particularly in the older age groups from 40 to 69 years. He considered that the low voltage EEG was of little diagnostic significance. However the 'flat' EEG of Adams and records characteristic of Huntington's chorea are different in that Adams used 20 $\mu \mathrm{V}$ rather than 10 as the amplitude criterion. In addition patients with Huntington's chorea may have EEGs practically devoid of any activity, not merely a paucity of recognizable rhythms. Adams noted that hyperventilation would increase the amount and amplitude of rhythmical activity; in patients with Huntington's chorea this does not seem to be the case. We believe that, while the low voltage record is not actually specific for Huntington's chorea, it is very uncommon in other neurological and psychiatric disorders and never occurs in normal subjects.

Not only had we observed the lack of spontaneous cerebral activity in patients with Huntington's chorea but also during visual examination of the routine EEG, photic stimulation was noted frequently to be without definite response. Thus an opportunity was taken to investigate the averaged evoked response by computer when it arose. This showed that EEG responses to visual and auditory stimulation were revealed by averaging. It is the first report to our knowledge of this examination in patients with Huntington's chorea.

The results of serial EEGs are also of interest. In spite of a small number of these, it would appear that, once the EEG becomes low voltage in Huntington's chorea, as it may do even 10 years before death, it remains devoid of activity. Only $33 \%$ of the present series of patients with Huntington's chorea had a low voltage record. This is probably an underestimate because of the stringent criteria used, also because any EEG that we could not re-examine personally was not included in the positive category. Nevertheless, a negative EEG result can be useful for the clinician, as it helps to exclude many other forms of presenile dementia with EEG changes-for example, Alzheimer's disease (Letemendia and Pampiglione, 1958), unrecognized temporal lobe epilepsy, and disturbance due to cerebrovascular disease or cerebral tumour.

Neuropathological EEG relationships proved of interest in this study because all 14 who had neuropathological examination showed characteristic atrophic changes in the basal ganglia as 
well as in the cerebral cortex, including the frontal lobe in most. This confirmed the observation of Hill (1948) that 'an atrophic process in the frontal cortex and in the basal ganglia is a significant factor (in producing absence of rhythmical activity) since neither alone produces persistent depression or facilitation of cortical rhythms'.

A possible association between parietooccipital atrophy, the region from which alpha activity is normally best seen, did not prove to be of significance.

The present study is concerned only with patients who had confirmed disease and we did not attempt to examine relatives to predict whether or not they would develop this disease in the way that Patterson, Bagchi, and Test (1959) and Chandler (1966) did, nor have we used provocative techniques such as the administration of L-dopa in relatives with a view to inducing involuntary movements in potentially afflicted individuals (Klawans, Paulson, and Barbeau, 1970). Nevertheless, in a small number of patients the positive EEG appeared early in the illness and it could occur as soon as 11 years before death. It is therefore possible that examination of relatives with early or doubtful clinical features may still be worthwhile at least on a research basis.

We would like to thank the many neurologists, physicians, and psychiatrists who have referred patients for study and given ready access to case histories and other information. We thank particularly Dr. June Dickson, Dr. N. de M. Rudolf, and Dr. H. Townsend who with their staff carried out most of the recordings and allowed us to study them. There are many others too numerous to name who have furnished information and EEGs. Our special thanks go to Dr. J. A. N. Corsellis at Runwell Hospital who undertook most of the neuropatho- logical studies and, for the others, to Professor H. Urich at the London Hospital. In addition, we are grateful to Dr. F. Tyson, Medical Director, Rochester State Hospital, Minnesota, who allowed us to study three patients, and to Dr. R. G. Bickford who provided evoked potential equipment used to carry out these special studies on them.

\section{REFERENCES}

Adams, A. (1959). Studies on the flat electroencephalogram in man. Electroencephalography and Clinical Neurophysiology, 11, 35-41.

Bickford, R. G., Jacobson, J. L., and Cody, D. T. R. (1964). Nature of average evoked potentials to sound and other stimuli in man. Annals of New York Academy of Sciences, 112, 204-218.

Chandler, J. H. (1966). EEG in prediction of Huntington's chorea. An eighteen year follow-up. Electroencephalography and Clinical Neurophysiology, 21, 79-80.

Gibbs, F. A., and Gibbs, E. L. (1941). Atlas of Electroencephalography. Cummings: Cambridge, Mass.

Heathfield, K. W. G. (1967). Huntington's chorea. Investigation into the prevalence of this disease in the area covered by the North East Metropolitan Regional Hospital Board. Brain, 90, 203-232.

Heathfield, K. W. G., and Mackenzie, I. G. (1971). Huntington's chorea in Bedfordshire. Guy's Hospital Report. (In Press.)

Hill, D. (1948). Discussion of the electroencephalogram in organic cerebral disease. Proceedings of the Royal Societ of Medicine, 41, 242-248.

Klawans, H. C., Paulson, G. W., and Barbeau, A. (1970) Predictive test for Huntington's chorea. Lancet, 2, 1185 1186.

Leese, S. M., Pond, D. A., and Shields, J. (1952). A pedigree of Huntington's chorea. Annals of Eugenics, 17, 92-112.

Lesse, S., Hoefer, P. F. A., and Austin, J. H. (1958). Th5 electroencephalogram in diffuse encephalopathies. Archives of Neurology and Psychiatry, 79, 359-375.

Letemendia, F., and Pampiglione, G. (1958). Clinical and electroencephalographic observations in Alzheimer's disease. Journal of Neurology, Neurosurgery, and Psychiatry, 21, 167-172.

Margerison, J. H., and Scott, D. F. (1965). Huntington's chorea: clinical, EEG and neuropathological findings (Abstract). Electroencephalography and Clinical Neurophysiology, 19, 314.

Patterson, R. M., Bagchi, B. K., and Test, A. (1948). The prediction of Huntington's chorea: an electroencephalographic and genetic study. American Journal of Psychiatry, 104, 786-797. 